\title{
A Novel Technique for Filtration Avoidance in Continuous Crystallization
}

Nima Yazdanpanah, Steven T. Ferguson, Allan S. Myerson, and Bernhardt L. Trout*

Department of Chemical Engineering, Massachusetts Institute of Technology, Cambridge, Massachusetts 02139, United States

Novartis-MIT Center for Continuous Manufacturing, Cambridge, Massachusetts 02139, United States

Supporting Information

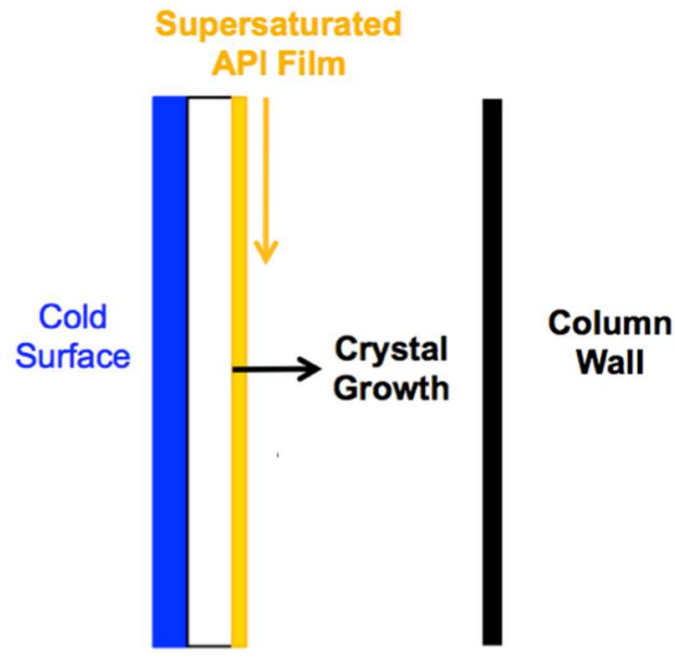

Figure S.1. Schematic diagram of the falling film methodology 


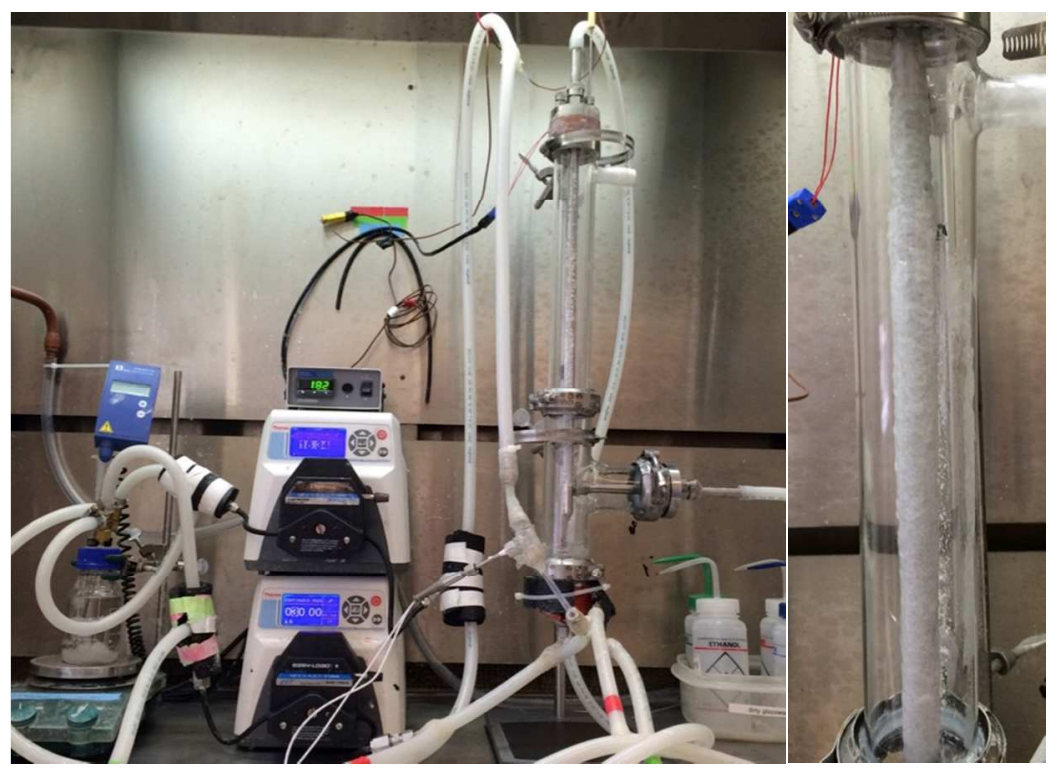

Figure S.2. A) Image of experimental falling film setup and B) the column with a deposited crystal layer.
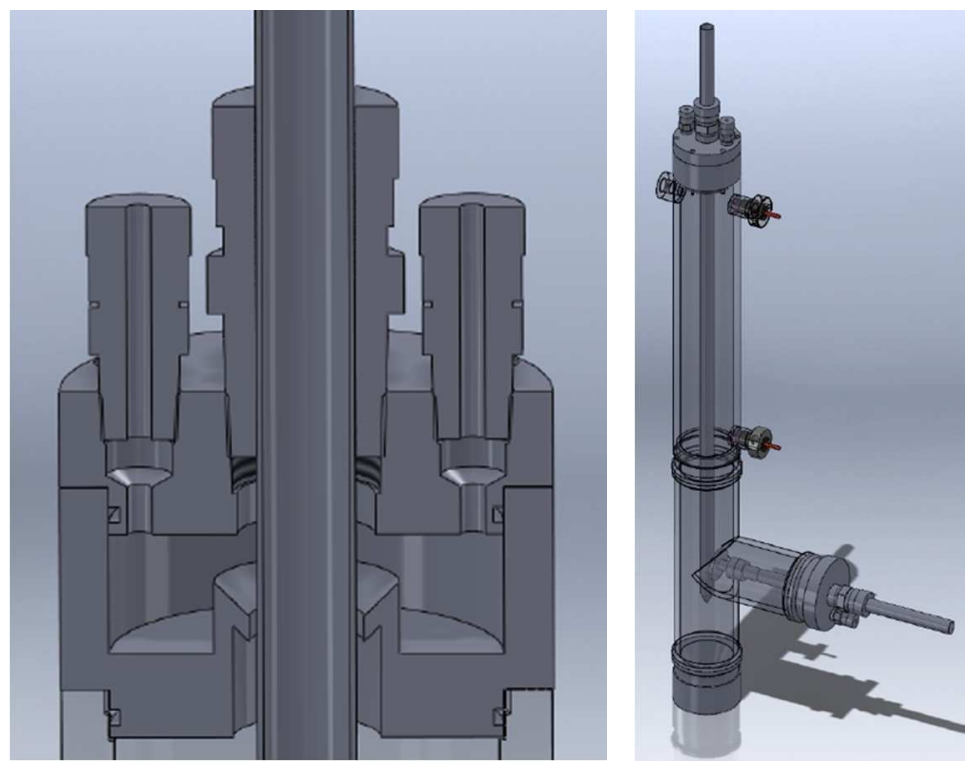

Figure S.3. A) Schematic diagram of the liquid distributor and B) the full column assembly. 